\title{
Exploring the field application of combined cognitive-motor program with mild cognitive impairment elderly patients
}

\author{
Sooyeon Kim* \\ Department of Sports Science, Ewha Womans University, Seoul, Korea
}

This study evaluated combined cognitive-motor program based on Alexander technique and Bartenieff fundamental method for mild cognitive impairment (MCI) patients. The purpose was to explore the field application of combined cognitive-motor learning program centering on proprioceptive neuromuscular facilitation, developing sensory-motor coordination and enhancing focused attention to one's whole body. Two practice methods were applied to the $40 \mathrm{MCl}$ elder. The combined cognitive-motor learning program (CM) was applied to the $20 \mathrm{MCI}$ elder while 20 elder took traditional movement learning program (TM). Mini Mental States Examination-Korea (MMSE-K), Time Up \& Go Test (TUG), Flexibility Test and Pegboard Test were measured and analyzed. The collected data were analyzed by paired $t$-test. The results were as follows: Both groups showed similar learning effect in Flexibility Test and
Pegboard Test. However, in MMSE-K and TUG, CM group showed significant learning effect than TM group. Our data suggested body awareness and body consciousness through Alexander technique and Bartenieff fundamental program facilitated patients' kinaesthesia: sensory awareness and conscious control of the whole movement. From these results, we conclude that combined cognitive-motor learning program is valuable as alternative program for cognitive development as well as physical development of $\mathrm{MCl}$ elder.

Keywords: Mild cognitive impairment, Combined cognitive-motor program, Somatic education, Alexander technique, Bartenieff fundamental movement

\section{INTRODUCTION}

Successful aging involves freedom from disability along with high cognitive, physical, and emotional functioning. However, the number of people suffering from dementia elderly is associated with a radical decline of sensory-perception, cognition, motor ability, and memory functions. To support dementia population to live healthily for as long as possible has been globing issue concerning economic impact.

Since the neuropathology studies in mild cognitive impairment (MCI), a transition state between normal aging and dementia, is supposed to be less severe than in dementia, its associated cognitive decline might be less irreversible and respond more accessible to treatment (Lehmann et al., 2003). Therefore, cognitive training in MCI patients has frequently been shown during recent decades (Fernández-Ballesteros et al., 2003; Heyn et al., 2004).

Many studies for the MCI have shown that occupational therapy program has beneficial effects on cognitive performance (Hofmann et al., 2003). More recently, some studies employ motor learning programs as a method to enhance cognitive performance. Kattenstroth et al. (2010) examined the effect of long-term dancing activities in MCI elderly. From long-term dancing activities, MCI patients can preserve cognitive, motor and perceptual abilities and prevent them from degradation. However, it is hard to find a study about cognitive training through combined cognitive-motor program.

Recently, somatic movement, also called movement based embodied cognitive practices, like Alexander technique, Feldenkraise

\footnotetext{
${ }^{*}$ Corresponding author: Sooyeon Kim (i) https://orcid.org/0000-0003-3704-1597 Department of Sports Science, Ewha Womans University, 52 Ewhayeodae-gil, Seodaemun-gu, Seoul 03760, Korea

Tel \& Fax: +82-31-782-0683, E-mail: sooyeonkim76@gmail.com

Received: August 1, 2018 / Accepted: August 25, 2018
}

This is an Open Access article distributed under the terms of the Creative Commons Attribution Non-Commercial License (http://creativecommons.org/licenses/by-nc/4.0/) which permits unrestricted non-commercial use, distribution, and reproduction in any medium, provided the original work is properly cited. 
and Bartenieff fundamental movement, is considered to be helpful for improving cognitive ability and mobility with Parkinson disease (Stallibrass et al., 2002; Stallibrass et al., 2005). Based on somatic movement studies with Parkinson disease, it is considered to explore somatic movement program for MIC patients.

This study evaluated combined cognitive-motor program based on somatic movement methods; Alexander technique and Bartenieff fundamental for MCI patients. The purpose was to explore the field application of combined cognitive-motor learning program centering on proprioceptive neuromuscular facilitation, developing sensory-motor coordination and enhancing focused attention to one's whole body.

\section{MATERIALS AND METHODS}

\section{Participants}

For this study, 40 participants were identified and recruited voluntarily at the Seoul Seongbuk Center for dementia. They underwent an evaluation by a neurologist and completed a Mini Mental States Examination-Korea (MMSE-K). Forty participants were divided into two groups, combined cognitive-motor practice group $(\mathrm{CM}, \mathrm{n}=20)$ and traditional movement practice group (TM, $\mathrm{n}=$ 20).

\section{Combined cognitive-motor program description}

The combined cognitive-motor program consists from Alexander technique and Bartenieff fundamental movement for sensing proprioception, developing sensory-motor coordination and enhancing focused attention to specific body part. The CM program was conducted by a certified Alexander technique and Bartenieff fundamental educator. Each of the programs, 1-hr session included Alexander technique and Bartenieff fundamental basic movement. In brief, sessions included a warm up (10 min), Alexander technique movement (15 min), Bartenieff fundamental movement (15 min), training of activities of daily living (10 min), and conclusion (10 min). Movement concept and specific movements of Alexander technique and Bartenieff fundamental movement were as follow (Tables 1, 2).

Table 1. Movement concept and specific movements of Alexander technique

\begin{tabular}{lcc}
\hline Movement concept & Goal movement & Activity \\
\hline Primary control & Head \& spine coordination & Rotation \& rolling \\
Direction & Torso & Breathing \\
Inhibition & Pelvis & Sit to stand \\
Means-Whereby & Eye \& head coordination & Eye tracking \\
\hline
\end{tabular}

\section{Procedure}

All participants were informed preliminary how to perform the experimental task and participate the program. They were randomly assigned into two groups as CM group and TM group. All participants performed MMSE-K, Time Up \& Go test (TUG), flexibility task, Pegboard test as a pretest in order to examine the differences of cognitive and motor ability between the two groups prior to the program. For safety reasons, an assessor remained near the participant without touching or providing additional instructions during the test. After intervention program, all participants performed MMSE-K, TUG, flexibility task, Pegboard test as a posttest.

\section{Statistical analysis}

In the pretest, comparing differences between $\mathrm{CM}$ and $\mathrm{TM}$ were analyzed using the independent sample $t$-test. The posttest was analyzed by the paired $t$-test, while mean differences between the groups in these variables were estimated using repeated measures analysis of variance. The IBM SPSS Statistics ver. 22.0 (IBM Co., Armonk, NY, USA) was used with the level of significance set at $P<0.05$.

\section{RESULTS}

\section{Cognitive ability \\ Pretest}

The independent samples $t$-test revealed no significant differences between CM group and TM group: $t(38)=-0.5815, P>0.05$. This result showed that there were no differences in cognitive ability between the two groups.

\section{Posttest}

We computed the mean of cognitive ability for the two groups (Fig. 1). When testing cognitive ability through MMSE-K by program types by independent samples $t$-test, we found no differ-

Table 2. Movement concept and specific movements of Bartenieff fundamental movement

\begin{tabular}{lcc}
\hline Developmental pattern & Goal movement & Activity pattern \\
\hline Breath & Core movement & Riding pattern \\
Core-distal & Navel radiation movement & Star fish pattern \\
Head-tail & Spinal movement & Pulling \& pushing pattern \\
Upper-lower & Homologous movement & Contraction \& release pattern \\
Body half & Homo-lateral movement & Open \& close pattern \\
Cross-lateral & Contra-lateral movement & Crawling pattern \\
\hline
\end{tabular}




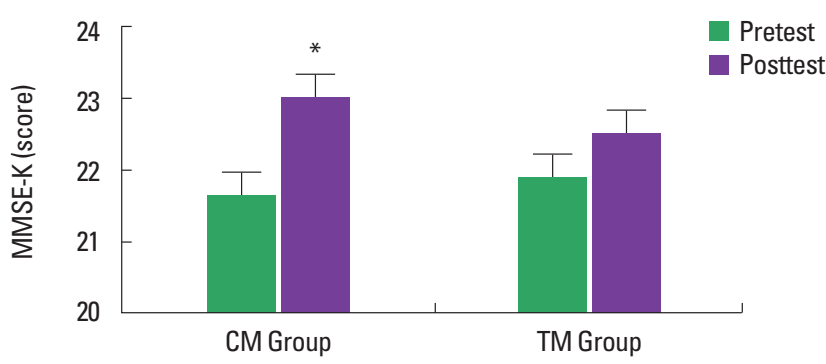

Fig. 1. Mini Mental States Examination-Korea (MMSE-K) score of two groups (Cognitive-motor program [CM], Traditional movement program [TM]) by learning pattern in pretest and posttest. ${ }^{*} P<0.05$, statistically significant difference between $\mathrm{CM}$ and TM groups.

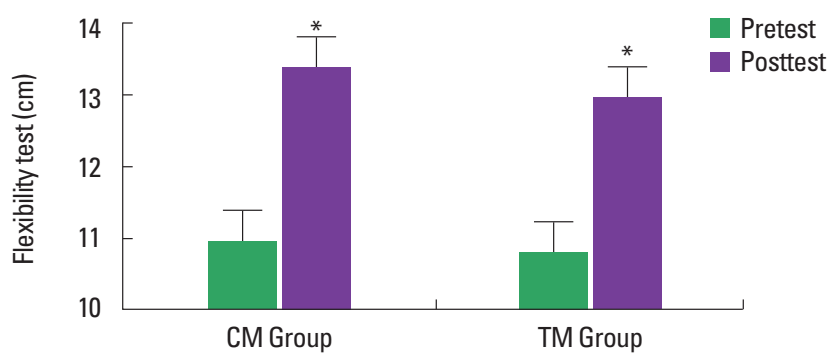

Fig. 2. Flexibility test score of two groups (Cognitive-motor program [CM], Traditional movement program [TM]) by learning pattern in pretest and posttest. ${ }^{*} P<0.05$, statistically significant differences compared to pretest.

ences between two groups $(t[38]=1.561, P>0.05)$. When evaluating cognitive ability within group by the paired $t$-test, we found differences between two groups. Compared to the control group, the $\mathrm{CM}$ group performed significantly better on cognitive ability in Posttest (CM group, cognitive ability: $t[19]=-3.439, P<0.05)$.

\section{Flexibility ability}

\section{Pretest}

The independent samples $t$-test revealed no significant differences between CM group and TM group: t $(38)=-0.676, P>0.05$. This result showed that there were no differences in Flexibility ability between the two groups.

\section{Posttest}

We computed the mean of flexibility ability for the two groups (Fig. 2). When testing flexibility ability by program types by independent samples $t$-test, we found no differences between two groups. $(t[38]=1.007, P>0.05)$. When evaluating flexibility ability within group by the paired $t$-test, both groups showed significant learning effect on flexibility ability in Posttest (CM group, flexibility ability: $t[19]=-3.439, P<0.05$, TM group, flexibility ability: $t[19]=-5.518, P<0.05)$.

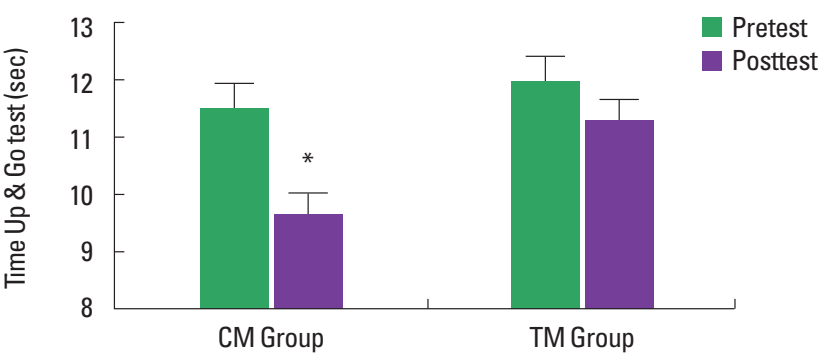

Fig. 3. Time Up \& Go test score of two groups (Cognitive-motor program [CM], Traditional movement program [TM]) by learning pattern in pretest and posttest. ${ }^{*} P<0.05$, statistically significant difference between CM and TM groups.

\section{Walking ability}

Pretest

The independent samples $t$-test revealed no significant differences between $\mathrm{CM}$ group and TM group: $t(38)=0.356, P>0.05$. This result showed that there were no differences in walking ability between the two groups.

\section{Posttest}

We computed the mean of walking ability for the two groups (Fig. 3). When testing walking ability through TUG by program types by independent samples $t$-test, we found no differences between two groups $(t[38]=-3.404, P<0.05)$. When evaluating walking ability within group by the paired $t$-test, we found differences between two groups. Compared to the control group, the $\mathrm{CM}$ group performed significantly better on walking ability in Posttest (CM group, balance ability: $t[19]=3.545, P<0.05$ ).

\section{Eye-hand coordination ability}

\section{Pretest}

The independent $t$-test revealed no significant differences between CM group and TM group: $t(38)=0.189, P>0.05$. This result showed that there were no differences in eye-hand coordination ability between the two groups.

\section{Posttest}

We computed the mean of eye-hand coordination ability for the two groups (Fig. 4). When testing eye-hand coordination through Pegboard test by program types by independent samples $t$-test, we found no differences between two groups $(t[38]=0.5815$, $P>0.05$ ). When evaluating eye-hand coordination ability within group by the paired $t$-test, both groups showed significant learning effect on eye-hand coordination ability in Posttest (CM group, eye-hand coordination ability: $t[19]=-10.804, P<0.05$, TM 


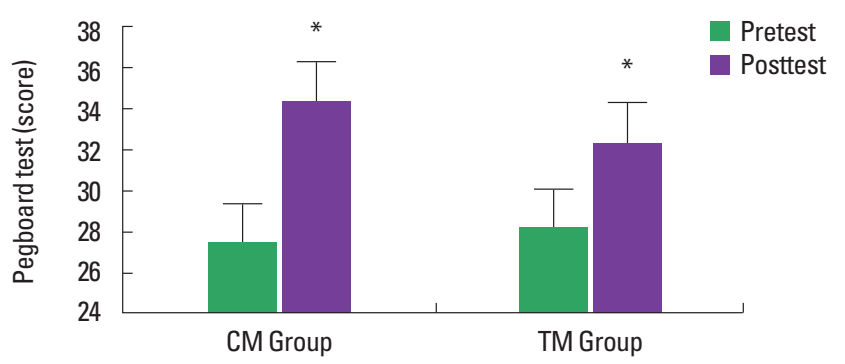

Fig. 4. Pegboard test score of two groups (Cognitive-motor program [CM], Traditional movement program [TM]) by learning pattern in pretest and posttest. ${ }^{*} P<0.05$, statistically significant differences compared to pretest.

group, flexibility ability: $t[19]=-7.030, P<0.05)$.

\section{DISCUSSION}

Studies of body awareness and body consciousness through lived body experience have been conducted as a kind of strategy to improve the performance skill in the field of performing arts. Galvao and Kemp (1999) showed that musicians' performance enhancement through the guidance of an Alexander technique. Result represented that uncontrolled musical reactions were adjusted by 'conscious control' with lived bodily experience. Current study showed similarities with Galvao and Kemp's (1999) study. Result showed that participants had improved Pegbaord test, which based on eye and hand coordination. Coordination between eye and hand is a kind of combined cognitive and motor task. Our data suggested body awareness and body consciousness through Alexander technique and Bartenieff fundamental program facilitated patients' kinaesthesia: sensory awareness and conscious control of the whole movement.

This study supported the cognitive-motor program's effect in terms of increasing in focused attention and interaction with environment. Levinoff et al. (2006) had addressed focused attention impairments in dementia's disease and suggested the need to explore the program concerning focused attention for dementia patients. In current study, CM program group showed decreased TUG score than TM program group with TUG score. TUG's reaction time provided a reliable psychological measure, showed perception and registration of an incoming sensory stimulus, motor response translation, decisional process and motor execution. It represented that intended sensory-motor coordination and perceptual benefits of active tactile touch in specific body part through cognitive-motor program developed patients' focused attention.

\section{CONFLICT OF INTEREST}

No potential conflict of interest relevant to this article was reported.

\section{ACKNOWLEDGMENTS}

This work was supported by the National Research Foundation of Korea Grant funded by the Korean Government (NRF2015S1A5B5A07044456).

\section{REFERENCES}

Fernández-Ballesteros R, Zamarrón MD, Tárraga L, Moya R, Iñiguez J. Cognitive plasticity in healthy, mild cognitive impairment (MCI) subjects and Alzheimer's disease patients: a research project in Spain. Eur Psychol 2003;8:148-159.

Galvao A, Kemp A. Kinaesthesia and instrumental music instruction: some implications. Psychol Music 1999;27:129-137.

Heyn P, Abreu BC, Ottenbacher KJ. The effects of exercise training on elderly persons with cognitive impairment and dementia: a meta-analysis. Arch Phys Med Rehabil 2004;85:1694-1704.

Hofmann M, Rösler A, Schwarz W, Müller-Spahn F, Kräuchi K, Hock C, Seifritz E. Interactive computer-training as a therapeutic tool in Alzheimer's disease. Compr Psychiatry 2003;44:213-219.

Kattenstroth JC, Kolankowska I, Kalisch T, Dinse HR. Superior sensory, motor, and cognitive performance in elderly individuals with multiyear dancing activities. Front Aging Neurosci 2010 Jul 21;2. pii: 31. https://doi.org/10.3389/fnagi.2010.00031. eCollection 2010.

Lehmann M, Regland B, Blennow K, Gottfries CG. Vitamin B12-B6-folate treatment improves blood-brain barrier function in patients with hyperhomocysteinaemia and mild cognitive impairment. Dement Geriatr Cogn Disord 2003;16:145-150.

Levinoff EJ, Phillips NA, Verret L, Babins L, Kelner N, Akerib V, Chertkow H. Cognitive estimation impairment in Alzheimer disease and mild cognitive impairment. Neuropsychology 2006;20:123-132.

Stallibrass C, Frank C, Wentworth K. Retention of skills learnt in Alexander technique lessons: 28 people with idiopathic Parkinson's disease. J Bodyw Mov Ther 2005;9:150-157.

Stallibrass C, Sissons P, Chalmers C. Randomized controlled trial of the Alexander technique for idiopathic Parkinson's disease. Clin Rehabil 2002;16:695-708. 